\title{
Healthy Lifestyle for Healthy Gums
}

\section{Hassija $\mathrm{J}^{\star}$ and Sridhar $\mathbf{N}$}

Manipal College of Dental Sciences, Manipal, Karnataka, India

*Corresponding author: Dr. Jyoti Hassija, MDS, Assistant Professor, Department of Prosthodontics, Crown and Bridge, Manipal College of Dental Sciences, Manipal, Karnataka, India, Tel: +91 9886932642; E-mail: j.hassija@gmail.com

Rec date: Jan 23, 2014, Acc date: May 01, 2014, Pub date: May 03, 2014

Copyright: ( 2014 Hassija J, et al. This is an open-access article distributed under the terms of the Creative Commons Attribution License, which permits unrestricted use, distribution, and reproduction in any medium, provided the original author and source are credited.

\begin{abstract}
When we think about dental health, focus is likely to be on preventing cavities, caries and decayed teeth but it's important to pay attention to gums too. Gums play a major role not only in dental health, but in overall well-being of a person. Gingival disease begins with bacterial growth in the mouth and may end- if not properly treated-with tooth loss due to destruction of the surrounding tissue.
\end{abstract}

Keywords: Dental health; Gingival disease; Gums

\section{Introduction}

As per a WHO global review of oral health, despite great improvements in the oral health of populations in several countries, gingival problems still persists. This is particularly so among underprivileged groups in both developing and developed countries. Oral diseases such as dental caries, periodontal disease, tooth loss and oral mucosal lesions are major public health problems worldwide [1].

\section{What Causes Gum Problems?}

Due to improper practice of dental hygiene, bacteria in the mouth form plaque on teeth. Biofilm formed by colonizing bacteria that accumulate naturally on the teeth release toxic substances that harm the gums and cause them to become infected. Infection and inflammation that result when body attacks the bacteria can degrade gums and surrounding bone. One may experience exceptionally swollen and painful gums that are likely to bleed.

Plaque and associated microflora have been widely accepted as the primary cause of gum disease [2-6]. However, another school of thought believes that the biofilm character of plaque allows for survival of a diverse flora, including less acid-tolerant organisms, some of which can produce ammonia from arginine or urea to counter acidification. Evidence is presented by certain authors that both supragingival and subgingival plaque have active oxygen metabolism and that plaque bacteria, including anaerobes, have developed defenses against oxidative stress. The finding that plaque bacteria produce a variety of protective enzymes is a good indicator that biofilm microflora may have some beneficial effects. The biofilm character of plaque allows for population diversity and coexistence of aerobes, anaerobes and microaerophiles. Agents that affect oxidative metabolism offer possibilities for reducing the pathogenic activities of plaque [7].

Apart from the contradictory viewpoints regarding etiological significance of biofilm for gingivitis, many other factors can contribute to or accelerate progression of periodontal disease. These include:

\section{Hormonal changes}

Such as those occurring during pregnancy, puberty, menopause and monthly menstruation make it easier for gingivitis to develop. Hormonal changes do not cause periodontal problems but may aggravate pre-existing disease. The most marked changes are seen in gingival vasculature [8].

\section{Illnesses and certain diseases}

This may affect the health of gingival tissues unfavorably. It is now becoming widely recognized that certain systemic diseases, such as osteoporosis, diabetes and immune disorders, may increase the risk for periodontal disease. Oral conditions, such as periodontal infections, may not only be indicators but also risk factors for important medical outcomes. This represents a paradigm shift in thinking about causality and the directionality of oral and systemic associations [9].

\section{Systemic medications}

These are known to cause Drug-induced gingival overgrowth. Three drugs are most frequently implicated with gingival inflammation are phenytoin, cyclosporine and the calcium channel blockers. Case reports have implicated other drugs (e.g. sodium valproate and erythromycin) but these are rare incidents [10].

A variety of risk factors for drug-induced gingival overgrowth have been extensively discussed in literature [11]. Essentially, they are age and other demographic variables, drug variables, concomitant medication, periodontal variables, and genetic factors.

Any plaque-induced inflammatory changes within tissues are going to exacerbate the expression of drug induced gingival overgrowth. This finding suggests causality, with a patient's oral hygiene being a significant risk factor for both the development and the expression of drug-induced gingival overgrowth [12-15], although reports to the contrary have also appeared [16-18]. Furthermore, most of the evidence supporting the relationship between bacterial plaque and drug-induced gingival overgrowth has been derived from crosssectional studies, and in such studies it is difficult to determine whether plaque is a contributory factor to or a consequence of the gingival changes. 
Although there may be some debate as to the role of plaque and gingival inflammation in drug-induced gingival overgrowth, there is no doubt that improving a patient's oral hygiene and reducing the inflammatory component in the gingival tissue by nonsurgical means does have an impact on this unwanted effect.

\section{Health behaviours}

The major health behaviors detrimental for gingival and periodontal health are smoking and use of other forms of tobacco, diets high in saturated fats and sugars and low in fibre, fruit and vegetables.

Not only oral disease but many other diseases which are increasing in industrialized and developing societies and are the main cause of premature morbidity and mortality are attributed at least in part to diet [19]. Numerous expert committees have concluded that particular diets, namely those high in saturated fatty acids, non-milk extrinsic sugars and low in polysaturates, fiber and vitamins $\mathrm{A}, \mathrm{C}$ and $\mathrm{E}$ are associated with conditions such as coronary heart disease, stroke, diabetes, cancers, obesity and oral disease [20-22]. Increasing scientific evidence from epidemiological, clinical and other relevant research has been accumulated to show that an unbalanced and processed food diet is a causative factor in a range of diseases, including gingival and periodontal disease.

Tobacco use is a risk factor for oral cancer, oral mucosal lesions, periodontal disease, impaired healing after periodontal treatment, gingival recession, and coronal and root caries. Available evidence suggests that the risks of oral disease increase with greater use of tobacco either in smoked or smokeless form.

Smoking makes it harder for gingival tissue to repair itself as it reduces blood supply. Deficiencies of neutrophil function often results in increased susceptibility to periodontitis in smokers [23].

Clinical parameters including probing pocket depth, clinical attachment loss were found to be increased in smokers compared to non-smokers. However, it is interesting to note that certain studies have shown decrease in bleeding on probing and reduced inflammatory response for plaque accumulation among smokers as compared to non-smokers [24,25]. These changes have been implicated, by various investigators, to altered microvasculature of the gingival connective tissue and increased thickness of epithelium among smokers, which mask the signs of inflammation [26-28].

The deleterious effects of smokeless tobacco use are perhaps not as well-known as those produced by smoking [29]. The relationship between smokeless tobacco use and periodontitis has also been the subject of scientific inquiry, although there are few such studies in comparison with many that have examined the association between smoking and periodontitis [30]. Smokeless tobacco use has been recognized as a cause of cancer [31]. Other oral effects of smokeless tobacco include leukoplakia, periodontal disease, and delayed wound healing and dental caries [32-36]. Individual cases of ANUG, gingivitis and periodontitis have also been reported [37], but a clear relationship does not exist between a generalized periodontal condition and smokeless tobacco use $[32,38]$. Gingival recession and attachment loss have been shown to occur in the area adjacent to where the smokeless tobacco is held [38-41], but some authors believe that gingival recession occurs only in smokeless tobacco users who exhibit coexisting gingivitis [37]. Gingival recession has been reported in smokeless tobacco users by many, but not all clinical surveys [38]. The recession has been postulated to be a result of mechanical injury from either the abrasive nature of smokeless tobacco products or from vigorous tooth brushing at the site of placement [42].

Electronic cigarettes are a relatively new addition to the family of nicotine containing products. These are battery-powered devices that convert nicotine into vapor [43].

E-cigarettes are new, so new, that the effects are relatively unknown. Effects of E-cigarettes on oral biology and health in general are catching attention of researchers in health fields. No conclusive studies have been done as of now to find out if nicotine vapors from these new age cigarettes can affect the oral flora and have gingival and periodontal effects similar to those of conventional smoking.

\section{Poor oral hygiene habits}

Such as not brushing and flossing on a daily basis, make it easier for gingivitis to develop.

\section{Family history of dental disease}

This can be a contributing factor for development of gingivitis. Despite meticulous oral hygiene habits, genetically susceptible individuals may be 6 times more likely to develop periodontal disease [44].

Adult periodontitis is estimated to have approximately $50 \%$ heritability, which remains unaltered following adjustments for behavioral variables including smoking [45].

\section{Signs and Symptoms}

More than three-quarters of Indian adults over the age of 35 suffer from some or other form of gum disease. While most people with gingival disease have the less severe form, called gingivitis, between 5 to $15 \%$ of the population has a much more serious type known as periodontitis. This ongoing process of destruction of soft and hard tissue surrounding the teeth may manifest as one or more of the following signs and symptoms:-

Red, swollen or tender gums

Sore and painful gums

Gums that bleed during or after tooth brushing

Persistent bad breath or bad taste in mouth

Receding gums

Loose or shifting teeth

Formation of deep pockets between teeth and gums

Stippling may disappear giving a smooth and shiny appearance to gums

In mild cases of gingivitis, patients may not even know they have it; however the condition should be taken seriously and addressed immediately.

\section{Professional and Home Care for Gingival Health}

Focus of prevention or treatment for gingivitis is on removal of the etiologic agent, plaque. Therapy is aimed at reduction of oral bacteria, and may take the form of regular periodic visits to a dentist along with adequate home care. 
Page 3 of 8

Although it may be possible under controlled conditions to remove most plaque with a variety of mechanical oral hygiene aids, many patients lack the motivation or skill to attain and maintain a plaquefree state for significant periods of time [46-48]. Clinical trials also indicate that self-administered plaque control programs alone, without periodic professional reinforcement, are inconsistent in providing long-term inhibition of gingivitis [49-51].

Many patients with gingivitis have calculus or other associated local factors (eg, defective dental restorations) that interfere with personal oral hygiene and the ability to remove bacterial plaque. An acceptable therapeutic result for these individuals is usually obtained when personal plaque control measures are performed in conjunction with professional removal of plaque, calculus, and other local contributing factors [52,53].

Removal of dental calculus is accomplished by scaling and root planing procedures using hand, sonic, or ultrasonic instruments. The therapeutic objective of scaling and root planing is to remove plaque and calculus to reduce subgingival bacteria below a threshold level capable of initiating clinical inflammation.

The success of instrumentation is determined by evaluating the periodontal tissues following treatment and during the maintenance phase of therapy.

The use of topical antibacterial agents to help reduce bacterial plaque may be beneficial for the prevention and treatment of gingivitis in some patients [54-56].

A number of these agents in oral rinses and dentifrices have been tested in clinical trials [54]. However, to be accepted by the American Dental Association (ADA) Council on Dental Therapeutics as an effective agent for the treatment of gingivitis, a product must reduce plaque and demonstrate effective reduction of gingival inflammation over a period of at least 6 months. The agent must also be safe and not induce adverse side effects.

Three medicaments have been given the ADA Seal of Acceptance for the control of gingivitis. The active ingredients of one product are thymol, menthol, eucalyptol, and methyl salicylate [55]. Active ingredients in the other two are chlorhexidine digluconate and triclosan [55]. If properly used, the addition of a topical anti-plaque agent to a gingivitis treatment regimen for patients with deficient plaque control will likely result in reduction of gingivitis [56]. However, experimental evidence indicates that penetration of topically applied agents into the gingival crevice is minimal [57]. Therefore, these agents are useful for the control of supragingival, but not subgingival plaque. Among individuals who do not perform excellent oral hygiene, supragingival irrigation with and without medicaments is capable of reducing gingival inflammation beyond that normally achieved by toothbrushing alone. This effect is likely due to the flushing out of subgingival bacteria [58].

Furthermore, oral Non-Steroidal Anti-Inflammatory Drug (NSAID) rinses are a relatively new treatment modality for treating inflammation in the oral cavity. NSAIDs such as ibuprofen or diclofenac can be used as mouthwashes to treat inflammation and infection of gums [59]. These drugs used in topical form are effective at alleviating pain and inflammation symptoms and are well tolerated in patients with painful inflammatory conditions of the oral cavity [60].

Recent line of NSAID research has focused on the development of daily topical administration forms such as gels, toothpastes and rinses, as many of the compounds like flurbiprofen are readily absorbed through the gingival tissues. In general, NSAIDs are lipophilic and easily penetrate into the oral and gingival tissues to rapidly inhibit local gingival crevicular fluid PGE 2 levels within $1 \mathrm{~h}[61,62]$. Topical administration of NSAID formulations helps overcome a wide range of systemic side effects such as gastric irritability, dyspepsia and more seriously gastric bleeding. Topical NSAIDs like $0.3 \mathrm{mg}$ flurbiprofen gel have shown benefit in the treatment of periodontitis [62]. Data on the efficacy of a topical ketorolac rinse have also been presented by Jeffcoat et al. [63] According to them, rinsing twice daily with $0.1 \%$ ketorolac tromethamine significantly reduces alveolar bone loss and gingival crevicular fluid PGE2 levels.

Diclofenac is a powerful anti-inflammatory and analgesic drug that is well suited for local use in the oral cavity. Diclofenac competes with arachidonic acid in a dose-dependent manner for binding with platelet COX. This results in decreased production of PG and thus reduces inflammation, swelling and pain. The drug also affects polymorphonuclear leukocyte function in vitro, thereby reducing chemotaxis, superoxide toxic radical production and neutral protease production and, thereby, reducing inflammation $[64,65]$. If the patient is diagnosed early on, and treatment is prompt and proper, gingivitis can be successfully reversed. Treatment involves care by a dental professional, and follow-up procedures carried out by the patient at home. Dentist explains to the patient importance of oral hygiene and educates him in appropriate brushing and flossing techniques. Maintenance phase of the treatment involves periodic follow up appointments. Periodic monitoring of periodontal status and appropriate maintenance procedures should be part of the long-term treatment plan for managing chronic periodontitis [54]. Although experimental studies have demonstrated very successful treatment outcomes when patients are professionally maintained at 2-week intervals [66], such a program is impractical for most chronic periodontitis patients. Therefore, to maximize successful therapeutic outcomes, patients must maintain effective daily plaque control. It also appears that in-office periodontal maintenance at 3 to 4 month intervals can be effective in maintaining most patients [67].

\section{Way to Healthy Gums}

Oral health is determined by diet, hygiene, habits, alcohol use, stress and trauma. In addition to socio-environmental determinants, gum disease is highly related to these lifestyle factors, as well as protective factors such as periodic dental visits and good oral hygiene. Gingivitis and periodontitis qualify as major public health problems owing to their high prevalence and incidence in all regions of the world, and as for all diseases, the greatest burden of these diseases is on disadvantaged and socially marginalized populations. Gingivitis can be prevented by performing a regular oral hygiene regime that includes daily brushing and flossing, along with a healthy diet and avoidance of substance abuse.

\section{Maintenance of oral hygiene}

Healthy habits and good oral hygiene, including daily brushing and flossing, are critical in preventing gum disease and maintaining good oral health.

Correct tooth brushing is the first defence against gingival and periodontal disease. It's worth investing some quality time educating and training the patient in healthy tooth brushing habits. Patients with gingival recession should be advised to avoid too frequent and 
vigorous brushing as it does not only deteriorate the local oral environment but can also lead to more serious consequences like systemic bacteremia if left unwatched. Transient bacteremias are well tolerated by healthy individuals but may increase endocarditis risk in patients with cardiac conditions. Patients who flossed daily developed no bacteremias but the patients who delayed flossing from 1 to 4 days developed bacteremias $86 \%$ of the time. It is important that patients who have a history of rheumatic fever and those who have internal prosthetic devices be cautioned regarding sporadic flossing [68].

In adults, the combination of twice-daily tooth brushing and daily flossing results in a $67 \%$ reduction in gingival bleeding; twice-daily tooth brushing alone results in a $35 \%$ reduction. Different techniques of toothbrushing have been evolved. Each technique has its pros and cons, but no technique is superior to others $[69,70]$. Current opinion favours the use of Bass method or modified Bass method, however choice is left to the patients as long as he /she is able to brush properly his/her teeth without injuring hard and soft tissues

Use of electric toothbrushes that rotate at $4200 \mathrm{times} / \mathrm{min}$ is recommended for those who lack manual dexterity. Powered toothbrushes with unique sensing and controlling technology have been found to have higher interproximal access efficacy compared to manual toothbrushes [71]. Power of these new generation tooth brushes is in terms of the number of strokes they provide to remove the accumulated plaque. Manual tooth brushes can provide just 300 strokes per minute in contrast to the 3,000 to 7,500 strokes per minute provided by electrically powered tooth brushes.

Interproximal devices, namely interproximal brushes, are more effective for reducing interproximal plaque and gingivitis than are flossing or brushing alone [72,73].

Toothbrushes should be replaced monthly to avoid harboring bacteria. A worn toothbrush is less effective than a new toothbrush for plaque removal and control of gingivitis [74].

Apart from mechanical cleaning aids which include tooth brushing, flossing and interproximal brushes, many authors have reported efficacy of indigenous agents like neem mouth rinse in reducing inflammatory effects of plaque induced gingivitis. 0.19\% Azadirachta indica (neem) has been found to have significant anti-inflammatory property. Thus, it can be used as an adjunct to mechanical therapy for treating plaque induced gingivitis [75,76]. Patel and Ventakrishna reported a significant reduction in probing depth and gain in clinical attachment level by its use [77].

$0.6 \%$ triphala mouth wash has been reported to reduce plaque scores, improve gingival health and have an inhibitory effect on bacterial count [77]. Triphla is Composed of the fruits of three trees, Indian gooseberry Amalaki (Embilica officinalis), Bibhitaki (Terminalia beleria), and Haritaki (Terminalia chebula), and is mentioned throughout the ancient literature of Ayurvedic medicine as a tonic, highly prized for its ability to regulate the process of digestion and elimination. Study done by Maurya et al. supports the use of Triphala for the cure of periodontal diseases [78]. Jagtap and Karkera have also tested the efficacy of Triphala mouthwash in the inhibition of Streptococcus counts and have reported promising results [79].

Green tea has also been studied to have inhibitory effect on periodontal pathogens and destructive periodontal diseases [80]. Epigallocatechin-3-gallate, a major ingredient of Green tea catechins , has been reported to exert a variety of biological effects, including antioxidant, antibacterial, anti-inflammatory and anticarcinogenic activities. Additionally, it has been reported that this ingredient inhibits lipopolysaccharide (LPS)-induced inflammatory cytokine production [81-83].

\section{Diet}

It's a well-documented fact that one becomes what he eats. Balanced diet is a crucial part of life style towards healthy non bleeding gums $[84,85]$. According to the American Dietetic Association, "nutrition is an integral component of gingival health [86]." Patients prone to gingivitis should be advised to eat a balanced diet rich in whole grains, fruit, and vegetables and practice good oral hygiene to maximize oral and systemic health.

Drinking plenty of water increases production of saliva, which has a protective effect on gingival health by reducing plaque accumulation.

If it is not possible to brush after eating sweets, rinsing the mouth with plain water can reduce the bacterial level by $30 \%$.

Probiotics, defined by WHO in 2002 as "live microorganisms which when administered in adequate amounts confer a health benefit on the host" [87] (WHO 2002) is the recent addition in the field of effects of diet on health. Traditionally, probiotics have been associated with gut health, and most clinical interest has been focused on their use for prevention or treatment of gastrointestinal infections and diseases; however, during the last decade several investigators have also suggested the use of probiotics for oral health purposes. Just as there are bacterial species associated with oral diseases, there are also species that seem to be associated with oral health [88-90]. The general mechanisms of probiotics can be divided into three main categories: normalization of the microbiota, modulation of the immune response, and metabolic effects [91,92]. Probiotic is chewing gums [93], probiotic tablets [94] and probiotic milk [95] and other dietary formulations containing microorganisms such as Lactobacillus reuteri [96] have been studied to combat inflammation in the oral cavity by reduction of pro inflammatory cytokines in gingival crevicular fluid (GCF).

The first studies of the use of probiotics for enhancing oral health were for the treatment of periodontal inflammation [97]. Patients with various periodontal diseases, gingivitis, periodontitis, and pregnancy gingivitis, were locally treated with a culture supernatant of a $L$. acidophilus strain. Significant recovery was reported for almost every patient. There has been significant interest in using probiotics in treatment of periodontal disease. The probiotic strains used in combating periodontal conditions include L. reuteri strains, L. brevis (CD2), L. casei Shirota, L. salivarius WB21, and Bacillus subtilis. L. reuteri and $L$. brevis. They have been reported to improve gingival health, as measured by decreased gum bleeding $[93,96,98]$. The use of probiotic chewing gum containing L. reuteri ATCC 55730 and ATCC PTA 5289 also decreased levels of pro-inflammatory cytokines in GCF, 100 and the use of $L$. brevis decreased collagenase activity and other inflammatory markers in saliva [98]. The use of $L$. casei Shirota decreased PMN elastase and MMP-3 activities in GCF, and gingival inflammation was lower in the group consuming the probiotic product, as measured by MPO activity after a four-day period of experimental gingivitis [99]. B. subtilis seemed to reduce the number of periodontal pathogens [100]. Use of tablets containing L. salivarius WB21 has been shown to decrease gingival pocket depth, particularly in high-risk groups such as smokers, and also affect the number of periodonto pathogens in plaque $[94,101]$. 
Page 5 of 8

Remineralisation potential, antiplaque and anti-gingivitis effects of xylitol and sorbitol sweetened chewing gums has also been well documented in literature. Consuming xylitol candies or chewing gums on a regular basis has been studied to reduce both Plaque and Gingival Index scores $[102,103]$. Prolonged use of xylitol or xylitol containing chewing gum acts by reducing Streptococcus mutans counts in plaque and saliva and at the same time fostering remineralization of early caries lesions. Regular use of xylitol does not only reduce the acidogenic potential and adhesiveness of plaque [104] but also increases its mineral content. Acid neutralizing properties of sugar free gums can be further accentuated by adding ingredients like chlorhexidine and ureum [105]. The plaque-growth retarding properties of Chlorhexidine-containing chewing gum have been shown to equal that of a Chlorhexidine mouthwash. Ureum added to a sugar-free chewing gum helps to neutralize plaque acids by liberating basic ammonia.

\section{Avoid substance abuse}

In addition to the general health risks posed by tobacco, alcohol and other types of substance abuse, they have a considerably detrimental effect upon gingival health.

In 'The World Oral Health Report' published by WHO, it is stated that "The rapidly changing (oral) disease patterns throughout the world are closely linked to changing lifestyles which include diets rich in sugars, widespread use of tobacco and increased consumption of alcohol"'[106].

Increase in the consumption of alcohol and intake of tobacco in smoked or smokeless form is the major cause of increase in prevelance and incidence of gingivitis and periodontitis.

Cigarette smokers have been found to have a statistically significant higher risk of severe periodontitis than non-tobacco users [107].

Alcohol abuse is also associated with increased likelihood of gingival disease. Occurrence of periodontitis among alcohol users is high and the frequency of alcohol consumption increases the odds of periodontitis incrementally mainly in smokers [108].

\section{Conclusion}

Healthy gums are a foundation not only for healthy teeth but for a healthy body as well. Three out of four people may suffer from gum disease during their lifetime, without even knowing it. If left untreated, gum problems can lead to severe and irreversible damage.

The first key to prevent periodontal conditions is considered to be a change in the health behavior of the individual. It is true that excessive drinking and smoking, overeating and faulty nutrition has deleterious effects on oral health [109].

The term "lifestyle" is taken to mean a general way of living based on the interplay between living conditions in the wide sense and individual patterns of behavior as determined by sociocultural factors and personal characteristics. The way in which an individual lives may produce behavioral patterns that are either beneficial or detrimental to health.

The concept of a healthy lifestyle being directly related to oral health has been stressed upon by several authors [110-112] in the past and they found that people with an active and healthy lifestyle had fewer symptoms in teeth and gums than those with inactive ones.
The concept of lifestyle is something more than behavior; it is a way of life and studied as broadly as possible. There is a strong association of lifestyle, education level, and socioeconomic position with periodontal diseases.

\section{References}

1. Shaju JP, Zade RM, Das M (2011) Prevalence of periodontitis in the Indian population: A literature review. J Indian Soc Periodontol 15: 29-34.

2. Albandar JM, Buischi YA, Mayer MP, Axelsson P (1994) Long-Term Effect of Two Preventive Programs on the Incidence of Plaque and Gingivitis in Adolescents. J Periodontol 65: 605-610.

3. Socransky SS, Haffajee AD (1992) The Bacterial Etiology of Destructive Periodontal Disease: Current Concepts. J Periodontol 63: 322-331.

4. American Academy of Periodontology (1999) The pathogenesis of periodontal diseases. J Periodontol 70: 457-470.

5. Page RC (1986) Gingivitis. J Clin Periodontol 13: 345-359.

6. Ranney RR, Debski BF, Tew JG (1981) Pathogenesis of gingivitis and periodontal disease in children and young adults. Pediatr Dent 3: 89-100.

7. Marquis RE (1995) Oxygen metabolism, oxidative stress and acid-base physiology of dental plaque biofilms. J Ind Microbiol 15: 198-207.

8. Figuero E, Carrillo-de-Albornoz A, Martín C, Tobías A, Herrera D (2013) Effect of pregnancy on gingival inflammation in systemically healthy women: a systematic review. J Clin Periodontol 40: 457-473.

9. Page RC (1998) Periodontal diseases: a new paradigm. J Dent Educ 62: 812-821.

10. Seymour RA, Heasman PA (1988) Drugs and the periodontium. J Clin Periodontol 15: 1-16.

11. Seymour RA, Ellis JS, Thomason JM (2000) Risk factors for drug induced gingival overgrowth. J Clin Periodontol 27: 217-223.

12. Ellis JS, Seymour RA, Steele JG, Robertson P, Butler TJ, et al. (1999) Prevalence of gingival overgrowth induced by calcium channel blockers: a community-based study. J Periodontol 70: 63-67.

13. King GN, Fullinfaw R, Higgins TJ, Walker RG, Francis DM, et al. Gingival hyperplasia in renal allograft recipients receiving cyclosporin-A and calcium antagonists. J Clin Periodontol 20: 286-293.

14. Pernu HE, Pernu LM, Huttunen KR, Nieminen PA, Knuuttila ML (1992) Gingival overgrowth among renal transplant recipients related to immunosuppressive medication and possible local background factors. J Periodontol 63: 548-553.

15. Somacarrera ML, Hernandez G, Acero J, Moskow BS (1994) Factors related to the incidence and severity of cyclosporine induced gingival overgrowth in transplant patients. A longitudinal study. J Periodontol 65: 671-675.

16. Schulz A, Lange DE, Stone CE, Lison AE (1990) Ciclosporin induzierte Gingivahyperplasie bei Patienten mit Nierentransplantaten. Dtsch Zahnarztl Z 45: 414-416.

17. Seymour RA, Smith DG, Rogers SR (1987) The comparative effects of azathioprine and cyclosporin on some gingival health parameters of renal transplant patients. A longitudinal study. J Clin Periodontol 14: 610-613.

18. Wondimu B, Dahllof G, Berg U, Modeer T (1993) Cyclosporin-Ainduced gingival overgrowth in renal transplant children. Scand J Dent Res 101: 282-286.

19. World Health Organization (1990) Diet, nutrition, and the prevention of chronic diseases. Report of a WHO Study Group. Technical Report Series No 797, Geneva.

20. National Advisory Council for Nutrition Education NACNE (1984) Proposals for nutritional guidelines for health education in Britain. The Health Education Council, London.

21. Department of Health (1989) Dietary sugars and human disease. Report of the Panel on Dietary Sugars of the Committee on Medical Aspects of Food Policy. Report No 37. HMSO, London. 
Page 6 of 8

22. Department of Health (1991) Dietary reference values for food energy and nutrients for the United Kingdom. Report of the panel on dietary reference values of the committee on medical aspects of food policy. Report No 41. HMSO, London.

23. Srinivas M, Chethana KC, Padma R, Suragimath G, Anil M, et al. (2012) A study to assess and compare the peripheral blood neutrophil chemotaxis in smokers and nonsmokers with healthy periodontium, gingivitis, and chronic periodontitis. J Indian Soc Periodontol 16: 54-58.

24. Tonetti MS (1998) Cigarette smoking and periodontal diseases etiology and management of disease. Ann Periodontol 3: 88-101.

25. Hidalgo RV (2003) Smoking and periodontal disease. Periodontol 20003 50-58.

26. Scardina GA, Messina P (2001) Morphological changes in microcirculation induced by chronic smoking habit: A video capillary study on gingival mucosa. J Periodontol 72: 1318-1323.

27. Bergstrom J, Persson L, Preber H (1988) Influence of cigarette smoking on vascular reaction during experimental gingivitis. Scand J Dent Res 96: 34-39.

28. Villa CC, Matorelli AF (2003) Smoking influences on the thickness of marginal epithelium. Pesqui Odontol Bras 17: 41-45.

29. Centers for Disease Control and Prevention (1993) Cigarette smokingattributable mortality and years of potential life lost - United States. 1990. MMWR Morb Mortal Wkly Rep 42: 645-649.

30. Amarasena N, Ekanayaka AN, Herath L, Miyazaki H (2002) Tobacco use and oral hygiene as risk indicators for periodontitis. Community Dent Oral Epidemiol 30: 115-123.

31. US Department of Health and Human Services (1989) Reducing the health consequences of smoking: 25 years of progress, a report of the surgeon general. Washington, DC: US Department of Health and Human Services.

32. American Academy of Periodontology position paper (1996) Tobacco use and the periodontal patient. J Periodontol 67: 51-56.

33. Little SJ, Stevens VJ, LaChance PA, Severson HH, Bartley MH, et al. (1992) Smokeless tobacco habits and oral lesions in dental patients. J Public Health Dent 52: 269-276.

34. McCann D (1989) Tobacco use and oral health. JADA 118: 18-25.

35. Mecklenburg RE, Greenspan D, Kleinman DV (1992) Tobacco effects in the mouth. Washington, DC: US Department of Health and Human Services. Public Health Service 92-3330.

36. Jones JK, Triplett RG (1992) The relationship of cigarette smoking to impaired intraoral wound healing: a review of evidence and implications for patient care. J Oral Maxillofac Surg 50: 237-239.

37. Offenbacher S, Weathers DR (1985) Effects of smokeless tobacco on the periodontal, mucosal and caries status of adolescent males. J Oral Pathol 14: 169-181.

38. Robertson PB, Walsh M, Greene J, Ernster VL, Grady D, et al. (1990) Peridontal effects associated with the use of smokeless tobacco. J Peridontol 61: 438-443.

39. Weintraub JA, Burt BA (1987) Periodontal effects and dental caries associated with smokeless tobacco use. Public Health Rep 102: 30-35.

40. Christen AG (1980) The case against smokeless tobacco: five facts for the health professional to consider. J Am Dent Assoc 101: 464-469.

41. Ernster VL, Grady DG, Greene JC, Walsh M, Robertson P, et al. (1990) Smokeless tobacco use and health effects among baseball players. JAMA 264: 218-224.

42. Fisher MA, Taylor GW, Tilashalski KR (2005) Smokeless tobacco and severe active periodontal disease, NHANES III. J Dent Res 84: 705-710.

43. McGill N (2013) Research on e-cigarettes examining health effects: Regulations due. The Nation's Health 43: 1-10.

44. Joseph Cristoforo (2010) Assessing risk for gum disease.

45. Michalowicz BS, Diehl SR, Gunsolley JC, Sparks BS, Brooks CN, et al. (2000) Evidence of a Substantial Genetic Basis for Risk of Adult Periodontitis. J Periodontol 71: 1699-1707.
46. De la Rosa M, Guerra JZ, Johnston DA, Radike AW (1979) Plaque growth and removal with daily toothbrushing. J Periodontol 50: 661-664.

47. MacGregor IDM, Rugg-Gunn AJ, Gordon PH (1986) Plaque levels in relation to the number of toothbrushing strokes in uninstructed English schoolchildren. J Periodont Res 21: 577-582.

48. Lang NP, Cumming BR, Löe H (1973) Toothbrushing fre-quency as it relates to plaque development and gingival health. J Periodontol 44: 396-405.

49. Suomi JD, Greene JC, Vermillion JR, Doyle J, Chang JJ, et al. (1971) The effect of controlled oral hygiene procedures on the progression of periodontal disease in adults: Results after third and final year. J Periodontol 42: 152-160.

50. Listgarten MA, Schifter CC, Laster L (1985) 3-year longitudinal study of the periodontal status of an adult population with gingivitis. J Clin Periodontol 12: 225-238.

51. Agerbaek N, Melsen B, Lind OP, Glavind L, Kristiansen B (1979) Effect of regular small group instruction per se on oral health status of Danish schoolchildren. Community Dent Oral Epidemiol 7: 17-20.

52. Tagge DL, O'Leary TJ, El-Kafrawy AH (1975) The clinical and histological response of periodontal pockets to root planing and oral hygiene. J Periodontol 46: 527-533.

53. Lövdal A, Arno A, Schei O, Waerhaug J (1961) Combined effect of subgingival scaling and controlled oral hygiene on the incidence of gingivitis. Acta Odontol Scand 19: 537-555.

54. Hancock EB (1996) Periodontal diseases: Prevention. Ann Periodontol 1: 223-249.

55. Mandel ID (1994) Antimicrobial mouthrinses: Overview and update. J Am Dent Assoc 125: 2S-10S.

56. Brecx M, Brownstone E, MacDonald L, Gelskey S, Cheang M (1992) Efficacy of Listerine, Meridol, and chlorhexidine as supplements to regular tooth-cleaning measures. J Clin Periodontol 19: 202-207.

57. Pitcher GR, Newman HN, Strahan JD (1980) Access to subgingival plaque by disclosing agents using mouth rinsing and direct irrigation. J Clin Periodontol 7: 300-308.

58. American Academy of Periodontology (2005) Position paper: The role of supra- and subgingival irrigation in the treatment of periodontal diseases. J Periodontol 76: 2015-2027.

59. Agarwal S, Mathur S, Kothiwale S, Benjamin A (2010) Efficacy and acceptability of $0.074 \%$ diclofenac-containing mouthwash after periodontal surgery: a clinical study. Indian J Dent Res 21: 408-412.

60. Serafini G, Trevisan S, Saponati G, Bandettini B (2012) Therapeutic efficacy and tolerability of the topical treatment of inflammatory conditions of the oral cavity with a mouthwash containing diclofenac epolamine: a randomized, investigator-blind, parallel-group, controlled, phase III study. Clin Drug Investig 32: 41-49.

61. Salvi GE, Williams RC, Offenbacher S (1997) Nonsteroidal antiinflammatory drugs as adjuncts in the management of periodontal diseases and peri-implantitis. Curr Opin Periodontol 4: 51-58.

62. Williams RC, Jeffcoat MK, Howell TH, Reddy MS, Johnson HG, et al (1988) Topical flurbiprofen treatment of periodontitis in beagles. J Periodontal Res 23: 166-169.

63. Jeffcoat MK, Reddy MS, Haigh S, Buchanan W, Doyle MJ, et al. (1995) A comparison of topical ketorolac, systemic flurbiprofen, and placebo for the inhibition of bone loss in adult periodontitis. J Periodontol 66: 329-338.

64. Friman C, Johnston C, Chew C, Davis P (1986) Effect of diclofenac sodium, tolfenamic acid and indomethacin on the production of superoxide induced by $\mathrm{N}$-formyl-methionyl-leucyl-phenylalanine in normal human polymorphonuclear leukocytes. Scand J Rheumatol 15: 41-46.

65. Wildfeuer A (1983) Effects of non-steroidal anti-inflammatory drugs on human leukocytes. Z Rheumatol 42:16-20.

66. Rosling B, Nyman S, Lindhe J, Jern B (1976) The healing potential of the periodontal tissues following different techniques of periodontal surgery in plaque-free denti-tions. J Clin Periodontol 3: 233-250. 
67. Ramfjord SP (1993) Maintenance care and supportive periodontal therapy. Quintessence Int 24: 465-471.

68. Carroll GC, Sebor RJ (1980) Dental Flossing and Its Relationship to Transient Bacteremia. J Periodontol 51: 691-692.

69. Barrieshi-Nusair K, Alomari Q, Said K (2006) Dental health attitudes and behavior among dental students in Jordan. Community Dent Health 23: 147-151.

70. Schlueter N, Klimek J, Saleschke G, Ganss C (2010) Adoption of a toothbrushing technique: a controlled, randomised clinical trial. Clin Oral Investig 14: 99-106.

71. Kemp JH, Barnes CM, Spirgel CM, Shi X, Yankell SL (2012) Laboratory evaluation of plaque removal at interproximal sites by a specially engineered powered toothbrush with unique sensing and control technologies. J Clin Dent 23: 17-20.

72. Drisko CL (2013) Periodontal self-care: evidence-based support Periodontol 2000 62: 243-255

73. DE Slot, CE Do"rfer, GA Van der Weijden (2008) The efficacy of interdental brushes on plaque and parameters of periodontal inflammation: a systematic review Int J Dent Hyg 6: 253-264.

74. Warren PR, Jacobs D, Low MA, Chater BV, King DW (2002) A clinical investigation into the effect of toothbrush wears on efficacy J Clin Dent 13: 119-124.

75. Chatterjee A, Saluja M, Singh N, Kandwal A (2011) To evaluate the antigingivitis and antipalque effect of an Azadirachta indica (neem) mouthrinse on plaque induced gingivitis: A double-blind, randomized, controlled trial. J Indian Soc Periodontol 15: 398-401.

76. Botelho MA, Santos RC, Galberto J, Martins JG, Carvalho CO, et al. (2008) Efficacy of a mouthrinse based on leaves of the neem tree (Azadirachta indica) in the treatment of patients with chronic gingivitis: A double-blind, randomized, controlled trial. J Med Plants Res 2: 341-346.

77. Bajaj N, Tandon S (2011) The effect of Triphala and Chlorhexidine mouthwash on dental plaque, gingival inflammation, and microbial growth Int J Ayurveda Res 2: 29-36.

78. Maurya DK, Miltal N, Sharma KR, Nath G (1997) Role of Triphala in management of periodontal disease. Anc Sci Life 17: 120-127.

79. Jagtap AG, Karkera SG (1999) Potential of the aqueous extract of Terminalia chebula as an anticaries agent. J Ethnopharmacol 68: 299-306.

80. Deshpande N, Deshpande A, Mafoud S (2012) Evaluation of intake of green tea on gingival and periodontal status: An experimental study. Journal of Interdisciplinary Dentistry 2:108-112.

81. Singh BN, Shankar S, Srivastava RK (2011) Green tea catechin, epigallocatechin-3-gallate (EGCG): Mechanisms, perspectives and clinical applications. Biochem Pharmacol 82: 1807-1821.

82. Cooper R (2012) Green tea and theanine: Health benefits. Int J Food Sci Nutr 63: 90-97.

83. Connors SK, Chornokur G, Kumar NB (2012) New Insights into the Mechanisms of Green Tea Catechins in the Chemoprevention of Prostate Cancer. Nutr Cancer 64: 4-22.

84. Walls AW, Steele JG (2004) The relationship between oral health and nutrition in older people. Mech Ageing Dev 125: 853-857.

85. Budtz-Jørgensen E, Chung JP, Rapin CH (2001) Nutrition and ora health. Best Pract Res Clin Gastroenterol 15: 885-896.

86. Touger-Decker R, Mobley CC, American Dietetic Association (2003) Position of the American Dietetic Association: Oral health and nutrition. J Am Diet Assoc 5: 615-625.

87. WHO (2002) Guidelines for the evaluation of probiotic food. London, ON, Canada.

88. Becker MR, Paster BJ, Leys EJ, Moeschberger ML, Kenyon SG, et al (2002) Molecular analysis of bacterial species associated with childhood caries. J Clin Microbiol 40: 1001-1009.

89. Stingu CS, Eschrich K, Rodloff AC, Schaumann R, Jentsch H (2008) Periodontitis is associated with a loss of colonization by Streptococcus sanguinis. J Med Microbiol 57: 495-499.
90. Riep B, Edesi-Neuss L, Claessen F, Skarabis H, Ehmke B, et al. (2009) Are putative periodontal pathogens reliable diagnostic markers? J Clin Microbiol 47: 1705-1711.

91. Kato I, Yokokura T, Mutai M (1983) Macrophage activation by Lactobacillus casei in mice. Microbiol Immunol 27: 611-618.

92. Parvez S, Malik KA, Ah Kang S, Kim HY (2006) Probiotics and their fermented food products are beneficial for health. J Appl Microbiol 100: 1171-1185.

93. Twetman S, Derawi B, Keller M, Ekstrand K, Yucel-Lindberg T, et al. (2009) Short-term effect of chewing gums containing probiotic Lactobacillus reuteri on the levels of inflammatory mediators in gingival crevicular fluid. Acta Odontol Scand 67: 19-24.

94. Shimauchi H, Mayanagi G, Nakaya S, Minamibuchi M, Ito $\mathrm{Y}$, et al. (2008) Improvement of periodontal condition by probiotics with Lactobacillus salivarius WB21: a randomized, double-blind, placebocontrolled study. J Clin Periodontol 35: 897-905.

95. Staab B, Eick S, Knöfler G, Jentsch H (2009) The influence of a probiotic milk drink on the development of gingivitis: a pilot study. J Clin Periodontol 36: 850-856.

96. Krasse P, Carlsson B, Dahl C, Paulsson A, Nilsson A, et al. (2006) Decreased gum bleeding and reduced gingivitis by the probiotic Lactobacillus reuteri. Swed Dent J 30: 55-60.

97. Kragen $H$ (1954) The treatment of inflammatory affections of the oral mucosa with a lactic acid bacterial culture preparation. Zahnarztl Welt 9: 306-308.

98. Della Riccia DN, Bizzini F, Perilli MG, Polimeni A, Trinchieri V, et al. (2007) Anti-inflammatory effects of Lactobacillus brevis (CD2) on periodontal disease. Oral Dis 13: 376-385.

99. Staab B, Eick S, Knofler G, Jentsch H (2009) The influence of a probiotic milk drink on the development of gingivitis: a pilot study. J Clin Periodontol 36: 850-856.

100. Subura S, Mizunuma H, Ishikawa S, Oyake I, Okabayashi M, et al. (2009) The effect of Bacillus subtilis mouth rinsing in patients with periodontitis. Eur J Clin Microbiol Infect Dis 28: 1353-1356.

101. Mayanagi G, Kimura M, Nakaya S, Hirata H, Sakamoto M, et al. (2009) Probiotic effects of orally administered Lactobacillus salivarius WB21containing tablets on periodontopathic bacteria: a double-blinded, placebo-controlled, randomized clinical trial. J Clin Periodontol 36: 506-513.

102. Shyama M, Honkala E, Honkala S, Al-Mutawa SA (2006) Effect of xylitol candies on plaque and gingival indices in physically disabled school pupils. J Clin Dent 17: 17-21.

103. Steinberg LM, Odusola F, Mandel ID (1992) Remineralizing potential, antiplaque and antigingivitis effects of xylitol and sorbitol sweetened chewing gum. Clin Prev Dent 14: 31-34.

104. Twetman S, Stecksén-Blicks C (2003) Effect of xylitol-containing chewing gums on lactic acid production in dental plaque from caries active pre-school children. Oral Health Prev Dent 1: 195-199.

105. Toors FA (1992) Chewing gum and dental health. Literature review. Rev Belge Med Dent 47: 67-92.

106. Petersen PE (2003) The World Oral Health Report 2003: continuous improvement of oral health in the 21st century - the approach of the WHO Global Oral Health Program. Community Dent Oral Epidemiol 31:3-24

107. Hugoson A, Rolandsson M (2011) Periodontal disease in relation to smoking and the use of Swedish snus: epidemiological studies covering 20 years (1983-2003). J Clin Periodontol 38: 809-816.

108. Lages EJ, Costa FO, Lages EM, Cota LO, Cortelli SC, et al. (2012) Risk variables in the association between frequency of alcohol consumption and periodontitis. J Clin Periodontol 39: 115-122.

109. Sakki TK, Knuuttila ML, Antilla SS (1998) Lifestyle, gender and occupational status as determinants of dental health behavior. J Clin Periodontol 25: 566-570.

110. Wiley JA, Camacho TC (1980) Lifestyle and future health: Evidence from the Alameda county study. Prev Med 9: 1-21. 
Citation: Hassija J, Sridhar N (2014) Healthy Lifestyle for Healthy Gums. Dentistry 4: 235. doi:10.4172/2161-1122.1000235

Page 8 of 8

111. Rajala M, Honkala E, Rimpela M, Lammi S (1980) Tooth brushing in relation to other health habits in Finland. Community Dent Oral Epidemiol 8: 391-395.
112. Revicki D, Sobal J, DeForge B (1991) Smoking status and the practice of other unhealthy behaviors. Fam Med 23: 361-364. 